\title{
Age-specific prevalence of serrated lesions and their subtypes by screening colonoscopy: a retrospective study
}

\author{
Hyun Young Kim ${ }^{1 *}$, Seon Mie Kim', Ji-Hyun Seo ${ }^{1}$, Eun-Ha Park ${ }^{1}$, Nayoung Kim ${ }^{1,2}$ and Dong Ho Lee ${ }^{1,2}$
}

\begin{abstract}
Background: Serrated lesions of the colorectum as categorized by pathology include hyperplastic polyps, sessile serrated adenomas without dysplasia, and traditional serrated adenomas with dysplasia. The aim of this study was to investigate the prevalence of various subtypes of serrated lesions by age.

Methods: In this study, 28,544 consecutive asymptomatic patients (aged 22-88 years) were evaluated during health check-ups involving colonoscopies performed by gastroenterologists at a single institution from 2005 to 2012.

Results: The adenoma detection rate during colonoscopies for patients aged $\geq 50$ years was $31.8 \%$ (25.0-35.8\%). The serrated lesion detection rate for patients aged $\geq 50$ years was $15.3 \%$ (10.5-19.6\%). Serrated lesions were detected in $15.1 \%$ of all patients with subtype prevalences of $14.7 \%$ for hyperplastic polyps, $0.5 \%$ for sessile serrated adenomas, and $0.1 \%$ for traditional serrated adenomas. The prevalence of conventional adenomas increased sharply with age (5.0\% in patients aged $20-29$ years, $10.9 \%$ in those aged $30-39$ years, $21.8 \%$ in those aged $40-49$ years, $29.5 \%$ in those aged $50-59$ years, $36.9 \%$ in those aged $60-69$ years, and $40.7 \%$ in those aged $\geq 70$ years) (trend $P=0.027$ ). In contrast, the prevalence of serrated lesions increased only slightly with age (10.0\% in patients aged $20-29$ years, $11.8 \%$ in those aged $30-39$ years, $14.8 \%$ in those aged $40-49$ years, $15.3 \%$ in those aged $50-59$ years, $16.8 \%$ in those aged 60-69 years, and $16.4 \%$ in those aged $\geq 70$ years) (trend $P=0.036$ ).
\end{abstract}

Conclusions: The screening colonoscopy detection rate of serrated lesions, including sessile serrated adenomas and traditional serrated adenomas, appears to be relatively high among young patients aged $<50$ years.

Keywords: Colonic polyp, Serrated lesions, Prevalence, Screening colonoscopy

\section{Background}

The incidence and mortality rates associated with colorectal cancer are rapidly rising in Korea [1]. The current Korean guidelines recommend the performance of screening colonoscopy beginning at age 50 years in the averagerisk population [2]. Screening colonoscopy reportedly facilitates early detection and prevention of colorectal cancer that develops from the adenoma-carcinoma pathway $[3,4]$. However, right-sided colorectal cancer that develops from the serrated pathway may be less effectively detected by screening colonoscopy [5].

\footnotetext{
* Correspondence: cecilup@naver.com

${ }^{1}$ Department of Internal Medicine, Seoul National University Bundang

Hospital, Seongnam-si, Gyeonggi-do, Korea

Full list of author information is available at the end of the article
}

Serrated lesions of the colorectum are classified into three heterogeneous categories according to the World Health Organization: conventional hyperplastic polyps, sessile serrated adenomas, and traditional serrated adenomas [6]. Serrated lesions have a distinct endoscopic appearance. Sessile serrated adenomas are flat or sessile, poorly demarcated, and waxy or pale, and they may be covered with a mucus cap. Traditional serrated adenomas are occasionally peduculated. The detection rate of serrated lesions is closely dependent on the endoscopist.

An effective colonoscopy is necessary for early diagnosis of colorectal cancer precursor lesions, adenomas, or serrated lesions. The adenoma detection rate has been validated by endoscopists as a predictor of interval cancer and a surrogate indicator of the quality of screening colonoscopy $[7,8]$. Wide variability in the adenoma detection

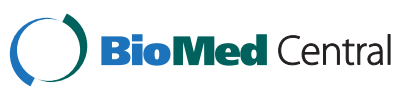


rate exists among endoscopists in previous studies $[9,10]$, and the adenoma detection rate has also shown a strong correlation with serrated lesion detection rate. Moreover, a recent study showed that the serrated lesion detection rate is an important indicator of the quality of colonoscopy [11].

The aim of this study was to investigate the prevalence of various serrated lesion subtypes according to age and assess the variability in the serrated lesion detection rate among expert endoscopists.

\section{Methods}

\section{Study population}

The study population comprised all patients who underwent colonoscopies in a single tertiary hospital (Seoul National University Bundang Hospital) from January 2005 to August 2012. In total, 28,544 asymptomatic patients aged 22 to 88 years at average risk for colorectal cancer underwent a complete screening colonoscopy. All patients filled out a questionnaire regarding their family history of colorectal cancer, physical activity, alcohol drinking habits, smoking habits, and hormone use. With respect to smoking, each patient was categorized as a neversmoker, former smoker, or current smoker. Seoul National University Bundang Hospital Health Promotion Center provided the various examination packages that were required, including that for colonoscopy. All screened patients underwent colonoscopy on a volunteer or employer-sponsored basis regardless of age; the most important issue among the study population was the cost of colonoscopy (\$US 60 in Korea). This study was approved by the Institutional Review Board of Seoul National University Bundang Hospital.

\section{Colonoscopy}

Four expert gastroenterologists ( $>1,000$ colonoscopies) who were certified by the Korean Society of Gastrointestinal Endoscopy and one nonexpert endoscopist $(<300$ colonoscopies) performed all endoscopies (CF-Q260AI/ AL; Olympus, Tokyo, Japan) with images displayed on standard-definition video monitors. Patients were excluded from the study if they had hereditary polyposis syndrome, inflammatory bowel disease, or an incomplete study. Bowel preparations comprised $4 \mathrm{~L}$ of polyethylene glycol-based or sodium phosphate-based solution. The proximal colon was defined as that portion proximal to the splenic flexure (transverse colon, ascending colon, cecum, and ileocecal valve). Polyps were pathologically defined as adenomas, serrated lesions, or carcinoid tumors. Adenomas were classified as tubular, tubulovillous, or villous adenomas with low- to high-grade dysplasia or as adenocarcinomas. Serrated lesions were classified as hyperplastic polyps, sessile serrated adenomas, or traditional serrated adenomas. Advanced adenomas were defined as large adenomas $(\geq 10 \mathrm{~mm}$ in size); adenomas with histopathological findings of tubulovillous, villous, or high-grade dysplasia; or adenocarcinoma. Endoscopists used the open-biopsy forceps method to estimate the size of the polyp or measure the actual size of the polyp after removal during colonoscopic polypectomy.

\section{Statistical analyses}

Data analyses were performed using SPSS software (version 18.0; SPSS Inc., Chicago, IL, USA). Continuous variables are expressed as mean \pm standard deviation, while categorical variables are expressed as absolute values and percentages. Continuous variables are presented as medians and ranges, and categorical variables are presented as percentages. Differences between variables were assessed by the $\chi^{2}$ test. All $P$ values were two-sided, and a $P$ value of $<0.05$ was considered statistically significant.

\section{Results}

This study included 28,544 patients $(17,357$ [60.8\%] men; mean age, $52 \pm 10$ years) who underwent health check-ups in a single endoscopy unit for screening colonoscopy. In total, 18,689 polyps were found in 10,358 of the 28,544 patients (36.3\% of patients). Among these polyps, $71.4 \%$ were proximal polyps and $5.0 \%$ were large polyps $(\geq 10 \mathrm{~mm})$. Serrated lesions accounted for $42 \%$ of all colonic polyps. Table 1 shows the differences in demographics and clinical characteristics between the patients with adenomatous polyps and those with serrated lesions. The patients with serrated lesions were more likely to be young, smokers (current or former), and alcohol drinkers $(P<0.001)$.

\section{Adenoma and serrated lesion detection rates by endoscopists}

Table 2 depicts the prevalence of adenomas and serrated lesions according to pathology, location, and size by colonoscopy. In total, 7,830 adenomas were detected in 28,544 patients $(27.4 \%)$, and 51 colorectal cancers were detected $(0.2 \%)$. The adenoma detection rate among patients of all ages was $27.4 \%$, whereas that in patients aged $\geq 50$ years was $31.8 \%$.

Table 3 depicts the adenoma and serrated lesion detection rates by endoscopists. The adenoma detection rate among patients of all ages was significantly correlated with the serrated lesion detection rate $(R=0.94, P=$ 0.020). There was a significant correlation between the adenoma and serrated lesion detection rates for patients aged $>50$ years $(R=0.93, P=0.022)$. The highest adenoma detection rate among all endoscopists was $35.8 \%$ in patients aged $\geq 50$ years. The adenoma detection rate differed between the four expert endoscopists (31.4\%-35.8\%) (endoscopists A, B, C, and D) and the nonexpert endoscopist (25.0\%) (endoscopist E). Adenomas were proximal in $5,150(65.8 \%)$ patients and distal in 4,904 (62.6\%) patients. The highest serrated lesion detection rate was $19.6 \%$ in 
Table 1 Demographics and baseline characteristics of patients

\begin{tabular}{|c|c|c|c|c|}
\hline & Any adenoma & Any serrated lesions & Adenoma \& SL & $P$ value \\
\hline Subjects, n & $7775(27.2 \%)$ & $4312(15.1 \%)$ & $1750(6.1 \%)$ & \\
\hline Age, mean, range, years & $55.2(25-88)$ & $51.4(22-83)$ & $55.5(27-82)$ & $<0.001$ \\
\hline Male, $\%$ & 67.7 & 67.9 & 81.8 & $<0.001$ \\
\hline Current or ex-smokers, $\%$ & 59.7 & 65.1 & 76.5 & $<0.001$ \\
\hline Alcohol use,\% & 71.8 & 75.5 & 21.3 & $<0.001$ \\
\hline Hormone use, $\%$ & 2.1 & 2.0 & 1.0 & 0.011 \\
\hline Family history of CRC,\% & 42.8 & 41.0 & 43.1 & 0.256 \\
\hline
\end{tabular}

CRC colorectal cancer, SL serrated lesions.

patients aged $\geq 50$ years. The overall serrated lesion detection rate was $15.3 \%$. In patients aged $\geq 50$ years, the serrated lesion detection rate ranged from $14.5 \%$ to $19.6 \%$ among the four expert endoscopists and the nonexpert endoscopist (10.5\%).

\section{Serrated lesion subtype detection rate and prevalence by age decade}

In total, 4,312 serrated lesions were detected in 28,544 patients $(15.1 \%)$. The hyperplastic polyp prevalence rate was $14.7 \%(n=4,187)$, the sessile serrated adenoma prevalence rate was $0.5 \%(n=143)$, and the traditional serrated adenoma prevalence rate was $0.1 \%(n=17)$. Serrated lesions were proximal in 2,241 (52.0\%) and distal in $3,444(79.9 \%)$ patients. Subtype analysis revealed that more hyperplastic polyps $(81.1 \%)$ and traditional serrated adenomas $(82.4 \%)$ were located in the distal colon, while more sessile serrated adenomas (86.0\%) were located in the proximal colon. Table 4 shows the serrated lesion prevalence by age category and sex. There was a steady trend in the prevalence of serrated lesions with increasing age (trend $P=0.036$ ) and an increasing trend in the prevalence of adenomas with age (trend $P=$ 0.027). The serrated lesion prevalence in patients aged 20 to 29 years was $10.0 \%(22 / 219)$, in those aged 30 to 39 years was $11.8 \%(300 / 2548)$, in those aged 40 to
49 years was $14.8 \%(1323 / 8960)$, in those aged 50 to 59 years was $15.3 \%(1529 / 9994)$, in those aged 60 to 69 years was $16.8 \%(888 / 5296)$, and in those aged $>70$ years was $16.4 \%(250 / 1527)$.

\section{Discussion}

The present cross-sectional analysis of serrated lesions of the colorectum at a single institution revealed the prevalence of various subtypes of serrated lesions by patient age and elucidated the detection rates among endoscopists during screening colonoscopies. The serrated lesion subtype prevalence in average-risk patients undergoing screening colonoscopy in the present study was similar to that previously reported. Serrated lesions were detected in $15.1 \%$ of patients, including $14.7 \%$ hyperplastic polyps, $0.5 \%$ sessile serrated adenomas, and $0.1 \%$ traditional serrated adenomas. Compared with a recently published study [9] with a detection rate of $11.7 \%$ for hyperplastic polyps, $0.6 \%$ for sessile serrated adenomas, and $0.2 \%$ for traditional serrated adenomas, our results emphasize the effect of screening colonoscopy on the detection rate of serrated lesion subtypes among gastroenterologists in a general population-based setting of young to old patients (range, 22-88 years of age). The age-specific prevalence of serrated lesions steadily increased with age, while that of conventional adenomas sharply increased with age.

Table 2 Polyp prevalence according to location and size by colonoscopy

\begin{tabular}{|c|c|c|c|c|c|c|}
\hline \multirow[t]{2}{*}{ Polyp histology } & \multirow{2}{*}{$\begin{array}{c}\text { Subjects } \\
10358 / 28544\end{array}$} & \multicolumn{2}{|c|}{ Location (\%) } & \multicolumn{3}{|c|}{ Size } \\
\hline & & Proximal (58.2\%) & Distal (41.8\%) & $\leq 9 \mathrm{~mm}$ & $10-20 \mathrm{~mm}$ & $>20 \mathrm{~mm}$ \\
\hline Adenoma & 7830 (27.4\%) & $5150(65.8 \%)$ & 4904 (62.6\%) & 7745 (98.9\%) & $311(4.0 \%)$ & $29(0.4 \%)$ \\
\hline Tubular, low grade & 7749 (27.1\%) & $5139(66.3 \%)$ & $4888(63.1 \%)$ & 7736 (99.8\%) & 302 (3.9\%) & $20(0.3 \%)$ \\
\hline Tubular, high grade & $19(0.1 \%)$ & $16(84.2 \%)$ & $14(73.7 \%)$ & 19 (100\%) & $1(5.3 \%)$ & $1(5.3 \%)$ \\
\hline Villous/tubulovillous & $11(0.03 \%)$ & $8(72.7 \%)$ & $9(81.8 \%)$ & $10(90.9 \%)$ & $5(45.5 \%)$ & 0 \\
\hline Adenocarcinoma & $51(0.2 \%)$ & $31(60.8 \%)$ & $42(82.4 \%)$ & $35(68.6 \%)$ & $21(41.2 \%)$ & $19(37.3 \%)$ \\
\hline Serrated lesions & $4312(15.1 \%)$ & $2241(52.0 \%)$ & $3444(79.9 \%)$ & 4309 (99.9\%) & $166(3.8 \%)$ & $9(0.2 \%)$ \\
\hline Hyperplastic & 4187 (14.7\%) & $2141(51.1 \%)$ & $3395(81.1 \%)$ & 4185 (99.9\%) & $162(3.9 \%)$ & $9(0.2 \%)$ \\
\hline Sessile serrated adenoma & $143(0.5 \%)$ & $123(86.0 \%)$ & $66(46.2 \%)$ & $142(99.3 \%)$ & $9(6.3 \%)$ & 0 \\
\hline Traditional serrated adenoma & $17(0.1 \%)$ & $10(58.8 \%)$ & $14(82.4 \%)$ & $17(100 \%)$ & $2(11.8 \%)$ & 0 \\
\hline Carcinoid & $26(0.1 \%)$ & $4(15.4 \%)$ & $25(96.2 \%)$ & $24(92.3 \%)$ & $1(3.8 \%)$ & $1(3.8 \%)$ \\
\hline
\end{tabular}


Table 3 Adenoma and serrated lesion detection rates by endoscopist

\begin{tabular}{lccccc}
\hline Endoscopist & $\mathbf{n}$ & ADR for all subjects (\%) & SDR for subjects (\%) & ADR for all subjects ( $\mathbf{2 5 0}$ years) (\%) & SDR for subjects ( $\mathbf{2 5 0}$ years) (\%) \\
\hline A & 6805 & 30.0 & 16.6 & 35.8 & 17.1 \\
B & 6461 & 26.9 & 13.5 & 31.4 & 14.6 \\
C & 5965 & 29.5 & 18.8 & 34.9 & 19.6 \\
D & 6757 & 26.2 & 14.6 & 31.8 & 14.5 \\
E & 2556 & 20.4 & 9.7 & 25.0 & 10.5 \\
mean & 28544 & $27.4(20.4-30.0)$ & $15.1(9.7-18.8)$ & $31.8(25.0-35.8)$ & $15.3(10.5-19.6)$ \\
$R, P$ value & \multicolumn{2}{r}{$R=0.94, P=0.020$} & $R=0.93, P=0.022$
\end{tabular}

$A D R$ adenoma detection rate, SDR serrated lesion detection rate, $R$ Pearson's correlation coefficient.

Colonoscopy with polypectomy significantly reduces the risk of death from colorectal cancer compared with the general population [6,12]. Colonoscopy does not reduce the incidence of death caused by right-sided colorectal cancer [13]. However, recent studies showed that a long-term effect of colonoscopy and a modest risk reduction for proximal colon cancer was achieved by colonoscopy in a United States cohort $[5,14]$ and German cohort [15]. Colonoscopy performed by a gastroenterologist was more protective against colorectal cancer mortality than was colonoscopy performed by other providers.

The adenoma detection rate of $\geq 20 \%(\geq 25 \%$ in men $\geq 50$ years of age and $\geq 15 \%$ in women $\geq 50$ years of age) during screening colonoscopy, which was developed as a quality indicator in 2002 [7], has now been validated as a powerful predictor of the colorectal cancer risk after screening colonoscopy. In a Polish study [8], the adenoma detection rate was associated with the risk of interval cancer during screening colonoscopy. However, $37.5 \%$ of those with adenoma detection rates of $<11 \%$ had colonoscopic experience of $>10$ years and $43 \%$ of those with adenoma detection rates $<11 \%$ for all endoscopists.

One editorial offered several potential explanations and possible solutions for the relatively poor protection offered by colonoscopy against right-sided colon cancer [16]. Some of these explanations included poor proximal colon protection in the form of poor bowel preparation, incomplete cecal intubation, failed detection of flat or depressed lesions, and failed detection of serrated lesions. These could be addressed by split dose preparation, documentation by landmarks, measurement of adenoma detection rates, measurement of serrated lesion detection rates, and education on detection of proximal colon serrated lesions. An ASGE/ACG Taskforce on Quality in Endoscopy proposed that effective endoscopists should achieve a cecal intubation rate of $\geq 90 \%$ of all cases and $\geq 95 \%$ of screening colonoscopies [17].

Another explanation for the relatively poor protection offered by colonoscopy against right-sided colon cancer is the continuum of molecular changes (CIMP, MSI, and $B R A F$ mutations) from the rectum to the ascending colon. This study has a substantial impact on the field of gastroenterology because of the prevalent dogma of proximal versus distal dichotomy, which is clearly an oversimplification $[18,19]$.

The serrated lesion detection rate has a wide range that is dependent on the endoscopist's experience and method. Two recent retrospective studies have evaluated the serrated lesion detection rate in average-risk patients

Table 4 Polyp prevalence by age and sex

\begin{tabular}{|c|c|c|c|c|c|c|c|c|c|}
\hline \multirow[t]{2}{*}{ Polyp histology } & \multirow{2}{*}{$\begin{array}{c}\text { Subjects } \\
10358 / 28544\end{array}$} & \multirow[t]{2}{*}{ Male (\%) } & \multicolumn{6}{|c|}{ Age } & \multirow[t]{2}{*}{ Trend $P$} \\
\hline & & & $\begin{array}{c}20-29 \\
(n=219)\end{array}$ & $\begin{array}{c}30-39 \\
(n=2548)\end{array}$ & $\begin{array}{c}40-49 \\
(n=8960)\end{array}$ & $\begin{array}{c}50-59 \\
(n=9994)\end{array}$ & $\begin{array}{c}60-69 \\
(n=5296)\end{array}$ & $\geq 70(n=1527)$ & \\
\hline Adenoma & $7775(27.2 \%)$ & $5511(70.9)$ & $11(5.0 \%)$ & $279(10.9 \%)$ & $1954(21.8 \%)$ & $2958(29.5 \%)$ & 1952 (36.9\%) & $621(40.7 \%)$ & 0.027 \\
\hline Tubular, low grade & 7749 (27.1\%) & $5498(71.0)$ & 11 & 279 & 1951 & 2948 & 1940 & 620 & \\
\hline Tubular, high grade & $19(0.1 \%)$ & $10(50)$ & 0 & 0 & 1 & 8 & 7 & 3 & \\
\hline Villous/tubulovillous & $11(0.03 \%)$ & $11(100)$ & 0 & 1 & 2 & 2 & 3 & 3 & \\
\hline Adenocarcinoma & $51(0.2 \%)$ & $36(70.6)$ & 0 & 0 & 5 & 14 & 26 & 6 & \\
\hline Serrated lesions & $4312(15.1 \%)$ & $3170(73.5)$ & $22(10.0 \%)$ & $300(11.8 \%)$ & $1323(14.8 \%)$ & $1529(15.3 \%)$ & $888(16.8 \%)$ & $250(16.4 \%)$ & 0.036 \\
\hline Hyperplastic & 4187 (14.7\%) & $3097(74.0)$ & 21 & 287 & 1277 & 1494 & 866 & 242 & \\
\hline Sessile serrated & $143(0.5 \%)$ & $86(60.1)$ & 1 & 18 & 50 & 45 & 29 & 5 & \\
\hline Traditional serrated & $17(0.1 \%)$ & $13(76.5)$ & 0 & 2 & 6 & 2 & 4 & 3 & \\
\hline Carcinoid & $26(0.1 \%)$ & $17(65.4)$ & 0 & 6 & 11 & 7 & 2 & 0 & \\
\hline
\end{tabular}


aged $\geq 50$ years during screening colonoscopy $[9,11]$. In a 2010 study [9], 7,192 colonoscopies at a single center were stratified by 13 endoscopists. The hyperplastic polyp detection rate ranged from $7.7 \%$ to $31.0 \%$, the sessile serrated adenoma detection rate ranged from $0.0 \%$ to $2.2 \%$, and the traditional serrated adenoma detection rate ranged from $0.0 \%$ to $0.5 \%$. Additionally, a 2012 study [11] described 6,681 colonoscopies performed by 15 endoscopists. The proximal serrated lesion detection rate ranged from $1.0 \%$ to $18 \%$. Our study showed a mean proximal serrated lesion detection rate of $7.9 \%$ with a narrowly ranged serrated lesion detection rate of $14.5 \%$ to $19.6 \%$ among the four expert gastroenterologists. However, the serrated lesion detection rate was wide when the nonexpert gastroenterologist was included $(10.5 \%-19.6 \%)$. This suggests the effect of the endoscopist's experience. The four expert endoscopists' numbers of years of experience were very similar since gastroenterology fellowship graduation (range, 9-10 years).

Our data demonstrate that serrated lesions tend to develop more frequently than conventional adenomas in younger patients (aged 20-39 years). The prevalence of conventional adenomas increased sharply with age $(5.0 \%$ in patients aged $20-29$ years, $10.9 \%$ in those aged $30-39$ years, $21.8 \%$ in those aged $40-49$ years, $29.5 \%$ in those aged $50-59$ years, $36.9 \%$ in those aged $60-69$ years, and $40.7 \%$ in those aged $\geq 70$ years). In contrast, the prevalence of serrated lesions increased only slightly with age (10.0\% in patients aged $20-29$ years, $11.8 \%$ in those aged $30-39$ years, $14.8 \%$ in those aged $40-49$ years, $15.3 \%$ in those aged $50-59$ years, $16.8 \%$ in those aged $60-69$ years, and $16.4 \%$ in those aged $\geq 70$ years). This difference in the age-specific prevalence between serrated lesions and conventional adenomas may be due to several factors. For example, as many as $15 \%$ of colorectal cancers occurred in patients $<50$ years of age, which is the age at which we routinely start performing screening colonoscopy for colon cancers. Additionally, serrated lesions may be contributors to $15 \%$ to $35 \%$ of cases of colorectal cancer development through the serrated polyp-carcinoma pathway $[3,4]$ and to the majority of cases of interval cancer development [20].

A strength of the current study is that it is the first to include patients in a young age category $(<50$ years of age) for evaluation of the serrated lesion prevalence using colonoscopy and precise categorization of the subtypes of serrated lesions. Importantly, it is the largest such study to date, comprising 28,544 patients who underwent screening colonoscopy to determine the age-specific prevalence of serrated lesions. An additional strength is that the majority of colonoscopies were performed by highly experienced endoscopists, producing high-quality data. All screened patients answered a questionnaire prior to colonoscopy, suggesting minimum recall bias. However, this study also has some limitations. Its main limitation is its cross-sectional, retrospective design, which introduces bias and leads to underestimation of the prevalence of small, left-sided hyperplastic polyps. A second limitation is the use of standard-definition white-light colonoscopes. Whether there is a significant difference between the detection rates of high- and standard-definition white-light colonoscopy remains unclear. A third limitation is that observer variation among pathologists in the diagnosis of serrated lesions could lead to underestimation of the true prevalence of sessile serrated adenomas and traditional serrated adenomas and thus to overestimation of the true prevalence of hyperplastic polyps.

\section{Conclusions}

The prevalence of serrated lesions, including sessile serrated adenomas and traditional serrated adenomas, appears to be relatively high among young patients aged $<50$ years by routine screening colonoscopy.

\section{Competing interests}

The authors declare that they have no competing interests.

\section{Authors' contributions}

HYK designed the study and drafted the manuscript. SMK, JHS, EHP, and $\mathrm{DHL}$ collected the clinical data. NK participated in the study design and coordination. All authors read and approved the final version of this manuscript.

\section{Acknowledgements}

This work was supported by grant No. 02-2012-070 from the Seoul National University Bundang Hospital.

\section{Author details}

${ }^{1}$ Department of Internal Medicine, Seoul National University Bundang Hospital, Seongnam-si, Gyeonggi-do, Korea. ${ }^{2}$ Department of Internal Medicine, Seoul National University College of Medicine, Seoul, Korea.

Received: 26 June 2013 Accepted: 23 April 2014

Published: 28 April 2014

\section{References}

1. Jung KW, Park S, Kong HJ, Won YJ, Boo YK, Shin HR, Park EC, Lee JS: Cancer statistics in Korea: incidence, mortality and survival in 2006-2007. J Korean Med Sci 2010, 25(8):1113-1121.

2. Lee BI, Hong SP, Kim SE, Kim SH, Kim HS, Hong SN, Yang DH, Shin SJ, Lee SH, Park DI, Kim YH, Kim HJ, Yang SK, Kim HJ, Jeon HJ, Multi-Society Task Force for Development of Guidelines for Colorectal Polyp Screening, Surveillance and Management: Korean guidelines for colorectal cancer screening and polyp detection. Clin Endosc 2012, 45(1):25-43.

3. Leggett $B$, Whitehall $V$ : Role of the serrated pathway in colorectal cancer pathogenesis. Gastroenterology 2010, 138(6):2088-2100.

4. Snover DC: Update on the serrated pathway to colorectal carcinoma. Hum Pathol 2011, 42(1):1-10.

5. Nishihara R, Wu K, Lochhead P, Morikawa T, Liao X, Qian ZR, Inamura K, Kim SA, Kuchiba A, Yamauchi M, Imamura Y, Willett WC, Rosner BA, Fuchs CS, Giovannucci E, Ogino S, Chan AT: Long-term colorectal-cancer incidence and mortality after lower endoscopy. N Engl J Med 2013, 369(12):1095-1105.

6. Rex DK, Ahnen DJ, Baron JA, Batts KP, Burke CA, Burt RW, Goldblum JR, Guillem JG, Kahi CJ, Kalady MF, O'Brien MJ, Odze RD, Ogino S, Parry S, Snover DC, Torlakovic EE, Wise PE, Young J, Church J: Serrated lesions of the colorectum: review and recommendations from an expert panel. Am J Gastroenterol 2012, 107(9):1315-1329. quiz 1314, 1330. 
7. Rex DK, Bond JH, Winawer S, Levin TR, Burt RW, Johnson DA, Kirk LM, Litlin S, Lieberman DA, Waye JD, Church J, Marshall JB, Riddell RH, U.S. Multi-Society Task Force on Colorectal Cancer: Quality in the technical performance of colonoscopy and the continuous quality improvement process for colonoscopy: recommendations of the U.S. Multi-Society Task Force on Colorectal Cancer. Am J Gastroenterol 2002, 97(6):1296-1308.

8. Kaminski MF, Regula J, Kraszewska E, Polkowski M, Wojciechowska U, Didkowska J, Zwierko M, Rupinski M, Nowacki MP, Butruk E: Quality indicators for colonoscopy and the risk of interval cancer. $N$ Engl J Med 2010, 362(19):1795-1803.

9. Hetzel JT, Huang CS, Coukos JA, Omstead K, Cerda SR, Yang S, O'Brien MJ, Farraye FA: Variation in the detection of serrated polyps in an average risk colorectal cancer screening cohort. Am J Gastroenterol 2010, 105(12):2656-2664.

10. Liang J, Kalady MF, Appau K, Church J: Serrated polyp detection rate during screening colonoscopy. Colorectal Dis 2012, 14(11):1323-1327.

11. Kahi CJ, Li X, Eckert GJ, Rex DK: High colonoscopic prevalence of proximal colon serrated polyps in average-risk men and women. Gastrointest Endosc 2012, 75(3):515-520.

12. Zauber AG, Winawer SJ, O'Brien MJ, Lansdorp-Vogelaar I, van Ballegooijen M, Hankey BF, Shi W, Bond JH, Schapiro M, Panish JF, Stewart ET, Waye JD: Colonoscopic polypectomy and long-term prevention of colorectal-cancer deaths. N Engl J Med 2012, 366(8):687-696.

13. Singh H, Nugent Z, Demers AA, Kliewer EV, Mahmud SM, Bernstein CN: The reduction in colorectal cancer mortality after colonoscopy varies by site of the cancer. Gastroenterology 2010, 139(4):1128-1137.

14. Baxter NN, Warren JL, Barrett MJ, Stukel TA, Doria-Rose VP: Association between colonoscopy and colorectal cancer mortality in a US cohort according to site of cancer and colonoscopist specialty. J Clin Oncol 2012, 30(21):2664-2669.

15. Brenner $\mathrm{H}$, Chang-Claude J, Seiler CM, Rickert A, Hoffmeister M: Protection from colorectal cancer after colonoscopy: a population-based, case-control study. Ann Intern Med 2011, 154(1):22-30.

16. Rex DK: Can we fix colonoscopy?...Yes! Gastroenterology 2011, 140(1):19-21.

17. Rex DK, Petrini JL, Baron TH, Chak A, Cohen J, Deal SE, Hoffman B, Jacobson BC, Mergener K, Petersen BT, Safdi MA, Faigel DO, Pike IM, ASGE/ACG Taskforce on Quality in Endoscopy: Quality indicators for colonoscopy. Am J Gastroenterol 2006, 101(4):873-885.

18. Yamauchi M, Morikawa T, Kuchiba A, Imamura Y, Qian ZR, Nishihara R, Liao X, Waldron L, Hoshida Y, Huttenhower C, Chan AT, Giovannucci E, Fuchs C, Ogino S: Assessment of colorectal cancer molecular features along bowel subsites challenges the conception of distinct dichotomy of proximal versus distal colorectum. Gut 2012, 61(6):847-854.

19. Yamauchi M, Lochhead P, Morikawa T, Huttenhower C, Chan AT, Giovannucci E, Fuchs C, Ogino S: Colorectal cancer: a tale of two sides or a continuum? Gut 2012, 61(6):794-797.

20. Brenner H, Chang-Claude J, Seiler CM, Hoffmeister M: Interval cancers after negative colonoscopy: population-based case-control study. Gut 2012, 61(11):1576-1582.

doi:10.1186/1471-230X-14-82

Cite this article as: Kim et al:: Age-specific prevalence of serrated lesions and their subtypes by screening colonoscopy: a retrospective study. BMC Gastroenterology 2014 14:82.

\section{Submit your next manuscript to BioMed Central and take full advantage of:}

- Convenient online submission

- Thorough peer review

- No space constraints or color figure charges

- Immediate publication on acceptance

- Inclusion in PubMed, CAS, Scopus and Google Scholar

- Research which is freely available for redistribution 